\title{
Infecciones en pacientes reumatológicos asociadas a corticosteroides y antagonistas del factor de necrosis tumoral $\alpha$
}

\author{
Alberto Fica
}

A great diversity of infectious agents can affect patients that use steroids at immunosuppressive doses or tumor necrosis factor $\alpha(\mathrm{TNF}-\alpha)$ antagonists. The list of participating microorganisms is more restricted in the case of anti TNF- $\alpha$ blockers. Overlapping agents include intracellular bacteria, Mycobacterium tuberculosis, geographic fungal agents that have the ability to establish granulamotous infections, herpes zoster, and reactivation of chronic hepatitis B virus infection. An important conceptual issue for these infections is the existence of a threshold prednisone daily dose for the emergence of opportunistic infections but higher levels of immunosuppression and cofactors are required in the case of Pneumocystis jiroveci and cytomegalovirus infections. In order to prevent these threats, a detailed medical evaluation is needed before prescription to detect potential risks and manage them properly. Prevention rules must be prescribed in every case, that include common sense behaviors, vaccines, and in selected cases, chemoprophylaxis for latent tuberculosis (TB) infection, $P$. jiroveci pneumonia (PCP) or other specific requirements. Latent TB infection is probable and requires chemoprophylaxis in the case of remote or recent exposure to a patient with lung TB, a positive tuberculin or interferon-gamma release assay result or residual lung scars in a chest X-ray exam. PCP prevention is suggested when the patient reaches a daily dose of prednisone of $30 \mathrm{mg}$ but might be needed at lower doses in case of other concomitant immunosuppressive drugs or when lymphopenia arises shortly after prednisone initiation.

Key words: Infection, glucocorticoids, tumor necrosis factor-alpha, rheumatoid arthritis, systemic lupus erythematosus, interferon-gamma release tests, tuberculosis.

Palabras clave: Infección, glucocorticoides, factor de necrosis tumoral $\alpha$, artritis reumatoidea, lupus eritematoso sistémico, prueba de liberación de gama interferón, tuberculosis.

\section{Introducción}

\section{L} as infecciones representan un tema frecuente entre los pacientes que usan corticosteroides o terapias biológicas indicadas para enfermedades del tejido conectivo tales como artritis reumatoide (AR) o lupus eritematoso sistémico (LES). Implican una gran carga de morbilidad adicional y en ocasiones son letales. La diversidad de productos aplicados, especialmente entre las terapias biológicas, junto a los múltiples agentes infecciosos potenciales, ameritan una revisión sobre este problema. Este artículo tiene como objetivo entregar una revisión actualizada sobre los riesgos asociados al uso de corticosteroides en dosis inmunosupresoras y a compuestos antagonistas del factor de necrosis tumoral $\alpha$ (FNT- $\alpha$ ), incluyendo además, aspectos preventivos.

\section{Infecciones asociadas a corticosteroides}

Los corticosteroides son utilizados en una variedad de condiciones clínicas que incluyen trasplante de órgano sólidos o de precursores hematopoyéticos, neoplasias hematológicas (leucemia, linfoma, mieloma múltiple), colagenopatías (LES, AR, otras) y enfermedades pulmonares crónicas (asma, EPOC, neumonía criptogénica organizada, enfermedades intersticiales) ${ }^{1}$.

Estos compuestos tienen diversos efectos sobre varias líneas celulares del sistema inmune. En el caso de los linfocitos inducen linfopenia, disminución de la proliferación y migración de los linfocitos, limitan la citotoxicidad mediada por las células NK (natural killers), disminuyen la producción de linfoquinas (IL-2, FNT $\alpha$, IL-12 e interferon- $\gamma$ ), alteran la función efectora fagocítica y la respuesta inmune celular, incluyendo la hipersensibilidad retardada. Producen, además, una reducción transitoria de los monocitos, alteran sus propiedades fagocíticas y de muerte oxidativa, disminuyen la quimiotaxis hacia sitios de inflamación, alteran la formación de óxido nítrico, bloquean la maduración de monocitos a macrófagos e inhiben la producción de citoquinas pro-inflamatorias. También afectan a los neutrófilos, alterando sus capacidades de fagocitosis, degranulación y estallido oxidativo, inhibiendo
Hospital Militar de Santiago, Chile.

Departamento de Medicina.

Servicio de Infectología.

Conflicto de interés: ninguno. Financiamiento: ninguno.

Recibido: 26 de agosto de 2013 Aceptado: 21 de noviembre de 2013

Correspondencia a: Alberto Fica Cubillos albertofica@gmail.com 
su producción de citoquinas, alterando también la formación de óxido nítrico y sus propiedades de quimiotaxis y extravasación al intersticio. Los glucocorticoides, afectan también la producción de prostaglandinas y la función presentadora de antígenos ${ }^{1}$. A pesar de sus innumerables bondades clínicas, favorecen la aparición de diversas infecciones y limitan nuestra capacidad para reconocer las manifestaciones clínicas o radiológicas de éstas ${ }^{1}$.

Las infecciones oportunistas asociadas a glucocorticoides aparecen cuando se asegura una dosis umbral. En una revisión sistemática, Stuck y cols., analizaron el riesgo de infecciones en 71 trabajos randomizados que evaluaban en forma secundaria este riesgo y lograron estimar un riesgo relativo de 1,6 en forma global $\left(\mathrm{IC}_{95} 1,3\right.$ a 1,9), es decir, aproximadamente $60 \%$ de riesgo adicional ${ }^{2}$. El riesgo resultó mayor en el subgrupo de pacientes neurológicos que recibieron corticosteroides ( $\mathrm{RR} 2,8 ; \mathrm{IC}_{95} 1,9$ a 4,3). Notablemente, este riesgo aparece cuando se ha acumulado una dosis de $700 \mathrm{mg}$ equivalente de prednisona o cuando un usuario crónico utiliza $>10 \mathrm{mg}$ de este compuesto en forma diaria ${ }^{2}$. El concepto de dosis umbral de corticosteroides como factor independiente, ha sido reproducido en numerosos otros trabajos y siempre cercano a los 10-15 $\mathrm{mg}$ de prednisona al día (dosis equivalente) ${ }^{3,4}$. El riesgo de

Tabla 1. Agentes infecciosos en pacientes inmunosuprimidos por corticosteroides

\begin{tabular}{|c|c|}
\hline Tipo de agentes & Ejemplos \\
\hline Bacterias & $\begin{array}{l}\text { Enterobacterias: Infecciones urinarias, bacteriemias } \\
\text { Staphylococcus aureus: bacteriemias, infecciones de piel y tejidos blandos } \\
\text { Streptococcus spp: bacteriemia, infecciones de piel y tejidos blandos } \\
\text { Salmonella spp: diarrea, bacteriemia } \\
\text { Legionella: neumonía } \\
\text { Listeria monocytogenes: bacteriemia, meningitis, romboencefalitis } \\
\text { Nocardia sp. neumonía, abscesos cerebrales, abscesos cutáneos } \\
\text { Rhodococcus equi: neumonia, abscesos, bacteriemia } \\
\text { Mycobacterium tuberculosis: tuberculosis } \\
\text { Clostridium difficile: diarrea }\end{array}$ \\
\hline Virus & $\begin{array}{l}\text { Virus respiratorios (varios): neumonía } \\
\text { Citomegalovirus: compromiso digestivo, pulmonar o SNC } \\
\text { Herpes simplex: formas diseminadas, infecciones crónicas, hepatitis } \\
\text { Varicela zoster: herpes zoster o varicela diseminada } \\
\text { Parvovirus B19: pancitopenia o síntomas de actividad lúpica. } \\
\text { Virus de la hepatitis B: riesgo de reactivación al inicio o retiro de los corticos- } \\
\text { teroides }\end{array}$ \\
\hline Hongos & $\begin{array}{l}\text { Candida spp: candidiasis de piel o mucosas y candidiasis sistémica } \\
\text { Cryptococcus sp: SNC, pulmonar, recaídas } \\
\text { Pneumocystis jiroveci: neumonía } \\
\text { Aspergillus spp: aspergilosis pulmonar invasora (en altas dosis) } \\
\text { Zygomycetes: mucormicosis rinocraneofacial o pulmonar (en altas dosis) }\end{array}$ \\
\hline Parásitos & $\begin{array}{l}\text { Toxoplasma gondii: toxoplasmosis (SNC, corio-retinitis, neumonía, diseminada) } \\
\text { Protozoos intestinales: Cryptosporidium sp., Giardia intestinalis, Entamoeba } \\
\text { histolytica (diarrea y disentería) } \\
\text { Nematodes: Strongyloides sp. (compromiso intestinal, hiperinfestación, formas } \\
\text { diseminadas) }\end{array}$ \\
\hline
\end{tabular}

infecciones oportunistas en pacientes con corticosteroides por vía inhalatoria es muy bajo y en forma localizada. Para pacientes con dosis equivalentes hasta $30 \mathrm{mg}$ al día de prednisona, se estima que el riesgo de infecciones varía entre 9 y 58 eventos cada 100 pacientes año, siendo mayor en el grupo con enfermedad inflamatoria intestinal que en pacientes con polimialgia reumática $o$ artritis reumatoide ${ }^{5}$. Esta dosis umbral puede ser algo menor $(\sim 10 \mathrm{mg} /$ día $)$ cuando concurren otros fármacos inmunosupresoras o co-morbilidades como por ejemplo diabetes mellitus y, por otra parte, pueden ser mayores para ciertos agentes como citomegalovirus o raras de observar en pacientes que sólo tienen enfermedad pulmonar obstructiva crónica.

Una diversidad de agentes comunes $\mathrm{u}$ oportunistas se asocia a infecciones en pacientes que reciben dosis inmunosupresoras de corticosteroides (Tabla 1$)^{6}$.

\section{Infecciones bacterianas}

Las enterobacterias, Staphylococcus spp y Streptococcus spp participan en infecciones habituales del tracto urinario, de piel o tejidos blandos o cuadros de bacteriemia. La tasa de eventos anuales en pacientes lúpicos alcanza a 0,17 episodios por año, predominando las infecciones urinarias con un tercio de estos eventos, luego infecciones pulmonares (cerca de $25 \%$ del total de infecciones) y de piel y tejidos blandos $(17 \%)^{7}$. Los pacientes con lupus activo, nefropatía o con corticosteroides tienen mayor incidencia de infecciones. En pacientes lúpicos, los eventos de bacteriemia se asocian mayoritariamente a bacilos gramnegativos y, con menor frecuencia, a $S$. aureus o Streptococcus spp. Los principales focos son el génito-urinario y catéteres vasculares con una tasa de letalidad mayor en aquellas bacteriemias asociadas a la atención de salud, particularmente mayor en las provocadas por bacilos gramnegativos no fermentadores. Las bacteriemias tienden a recurrir en al menos $10 \%$ de estos pacientes y la sobrevida de los pacientes con LES y bacteriemia se acorta ${ }^{8,9}$. Por su parte, los pacientes con AR representan un factor de riesgo independiente para el desarrollo de bacteriemias estafilocóccicas en la comunidad $^{10}$. La emergencia de Enterococcus spp resistentes a vancomicina en los hospitales también ha afectado a pacientes en tratamiento corticosteroidal ${ }^{11}$.

Un conjunto de patógenos intracelulares se asocian característicamente al uso de corticosteroides como salmonelas zoonóticas, Legionella sp y Listeria monocytogenes. Las infecciones por Salmonella spp incluyen serotipos zoonóticos y se expresan como diarrea o bacteriemia. Afortunadamente se asocian a menor mortalidad y menor compromiso extra-intestinal respecto a pacientes sin colagenopatías. ${ }^{12}$ Por su parte, las infecciones por Legionella sp se presentan como cuadros de neumonía grave y las de L. monocytogenes como eventos de bacteriemia o infecciones del SNC. Una serie recientemente 
publicada en Chile, señala que cerca de $30 \%$ de los pacientes con L. monocytogenes tenían inmunosupresión por corticosteroides ${ }^{13}$.

La tuberculosis (TBC) es un riesgo conocido en usuarios de corticosteroides, especialmente en pacientes que usan $\geq 15 \mathrm{mg}$ de prednisona al día. Otros factores independientes a la dosis diaria que concurren en estos pacientes son diabetes mellitus, un IMC $<20 \mathrm{~kg} / \mathrm{m}^{2}$, tabaquismo actual y EPOC ${ }^{14}$. La TBC en estos pacientes se presenta como cuadros pulmonares y con una alta frecuencia como formas extra-pulmonares ${ }^{15}$.

La nocardiosis se presenta como una conjunción de neumonía, lesiones cutáneas y/o lesiones cerebrales por este bacilo grampositivo ramificado ${ }^{16-18}$. También ha sido reportado en Chile en una paciente con $\mathrm{LES}^{19}$.

Aunque no es claro si los glucocorticoides aumentan el riesgo de diarrea por $C$. difficile, se sabe que se asocian a una mayor tasa de letalidad en pacientes hospitalizados que desarrollan diarrea por este agente ${ }^{20}$.

\section{Infecciones virales}

En términos globales, los pacientes con AR tienen mayor incidencia de influenza y de complicaciones por influenza respecto a controles pero este riesgo no está asociado al uso de fármacos modificantes o corticosteroides ${ }^{21}$. El uso de corticosteroides como antipirético aumentó el riesgo de muerte, falla respiratoria, shock, falla multiorgánica o ingreso a UCI en pacientes que consultaron por influenza pandémica $\mathrm{A} \mathrm{H} 1 \mathrm{~N} 1^{22}$. Las infecciones por otros virus respiratorios tales como adenovirus, virus respiratorio sincicial, metapneumovirus y parainfluenza tienden a ser más graves en pacientes con trasplante de órganos sólidos pero existe una escasa descripción respecto a su participación en pacientes inmunosuprimidos por corticosteroides en colagenopatías.

La exposición a corticosteroides aumenta el riesgo de reactivación del virus varicela-zoster en la forma de herpes zoster $^{6,23,24}$. La frecuencia de herpes zoster es aproximadamente tres veces superior a lo observado en otros pacientes con condiciones músculo-esqueléticas no inflamatorias y tiende a concentrarse poco después del diagnóstico pero no necesariamente se presenta en el momento de estar tomando fármacos inmunosupresore ${ }^{25}$.

Las infecciones por virus herpes simplex pueden generar cuadros de glositis o ulceraciones perianales recurrentes, hepatitis aguda o infecciones crónicas cutáneas en pacientes bajo terapia con glucocorticoides ${ }^{6,26-28}$. En ocasiones, formas diseminadas de infección por virus herpes simplex pueden simular un cuadro de varicela en pacientes con corticosteroides.

Citomegalovirus representa un importante agente viral oportunista que puede presentarse con compromiso digestivo, neumonía, encefalitis o cuadros de fiebre, leucopenia, trombocitopenia y ascenso de transaminasas hepáticas ${ }^{29}$.
Los pacientes con compromiso digestivo evidencian dolor abdominal, úlceras digestivas altas o bajas, rectorragia $\mathrm{y}$, en ocasiones, perforación intestinal. El diagnóstico en caso de compromiso digestivo requiere estudio endoscópico con biopsia y tinción inmunohistoquímica, con un escaso rendimiento para otras pruebas ${ }^{30,31}$. Las infecciones pulmonares se manifiestan como neumonitis, rara vez como cavitaciones, y el diagnóstico se puede intentar por reacción de polimerasa en cadena-RPC para CMV en lavado bronco-alveolar o con una prueba de antigenemia o carga viral elevada en sangre ${ }^{32,33}$. Los pacientes con corticoterapia que presentan infección por CMV lo hacen en los primeros 60 días del inicio de la terapia inmunosupresora y al parecer, con altas dosis diarias de prednisona (en el orden de $60 \mathrm{mg} /$ día) ${ }^{29}$.

Parvovirus B19 ha sido ligado a cuadros autolimitados que simulan LES, reactivaciones clínicas del LES y también al desarrollo de fiebre, artralgias, anemia y pancitopenia en pacientes con LES, con o sin anemia hemolítica de base $\mathrm{e}^{34,35}$. El diagnóstico puede establecerse por serología IgM específica o con amplificación del ADN viral por RPC en el mielograma ${ }^{34}$. La sobreposición con un cuadro de reactivación del LES induce al aumento de las dosis de corticosteroides pero ello empeora la anemia.

La corticoterapia aumenta el riesgo de reactivación de hepatitis B crónica luego de su inicio. Sin embargo, el aumento de transaminasas hepáticas ocurre sólo en la mitad de los pacientes, es muchas veces discreto y transitorio ${ }^{36}$. Para pacientes que no estaban en terapia antiviral, sólo una fracción de ellos $(\sim 20 \%)$ ha llegado a requerir terapia antiviral concomitante ${ }^{36}$. Rara vez los pacientes fallecen por esta co-infección.

No se dispone de datos directos sobre el impacto de los corticosteroides en pacientes con colagenopatías y hepatitis crónica por virus C. Para la población de pacientes con trasplante hepático, existe un mayor riesgo de progresión a cirrosis hepática y muerte en los primeros años post-trasplante y parte de este riesgo está asociado directamente el uso previo de bolos de metilprednisolona, lo que sugiere una combinación adversa de presentarse el caso ${ }^{37}$.

\section{Infecciones por hongos}

La aplicación de corticosteroides en dosis inmunosupresoras constituye un factor de riesgo para infecciones por levaduras ya sea candidiasis sistémica por C. albicans o C. no albicans o por Cryptococcus neoformans ${ }^{1}$, este último causando infección pulmonar o del SNC. La tasa de recaídas por este agente en infecciones del SNC aumenta si no se reduce la dosis de prednisona bajo el umbral inmunosupresor. Las infecciones del SNC por $C$. neoformans se presentan como cuadros de cefalea, compromiso de conciencia y cambios conductuales asociados a pleocitosis mononuclear y proteinorraquia moderadas, 
sin hipoglucorraquia y frecuentemente, alteraciones en el estudio de imágenes del $\mathrm{SNC}^{38,39}$. El cultivo es casi siempre positivo (98\%) pero de lenta obtención y el test de la tinta China sólo positivo en $50 \%$ de los casos. La detección de antígeno de $C$. neoformans es de muy alta sensibilidad y rápido tiempo de respuesta ${ }^{39}$. El cuadro suele ser de curso indolente, sin signos meníngeos y de mal pronóstico (mortalidad global aproximada: $30 \%)^{38,39}$.

Pneumocystis jiroveci es un hongo oportunista que se asocia a infecciones en pacientes que reciben corticosteroides. En pacientes con colagenopatías, la dosis umbral es más alta que para otros agentes oportunistas (>30 mg/día equivalente de prednisona), los pacientes habitualmente reciben otros fármacos inmunosupresores y además tienen linfopenia ${ }^{1,40,41}$. En comparación con pacientes con infección por VIH, las infecciones por $P$. jiroveci en pacientes sin infección por VIH suelen ser de curso aguda, muy graves y un alto porcentaje ingresa a UCI por falla respiratoria. Una fracción de estos casos se presenta durante la disminución de la dosis de corticosteroides ${ }^{42}$. Se estima que, al menos $6 \%$ de los pacientes con corticosteroides y enfermedades del tejido conectivo desarrollarán neumonía por $P$. jiroveci. El diagnóstico se establece por tinción histoquímica, inmunofluorescencia o RPC específica desde una muestra respiratoria, siendo la RPC a tiempo real el examen de mayor sensibilidad ${ }^{43}$. Cerca de la mitad de los pacientes presentan co-infección por otros agentes, incluyendo bacterias y virus ${ }^{41}$.

Las infecciones por Aspergillus spp y los casos de mucormicosis se favorecen con altas dosis de corticosteroides para su desarrollo, más propias de pacientes con trasplante alogénico de precursores hematopoyéticos o trasplante de órganos sólidos que de pacientes con enfermedades del tejido conectivo ${ }^{1}$. Los casos de mucormicosis reportados en Chile no se han asociado a este tipo de pacientes ${ }^{44}$. Para pacientes expuestos por residencia o viajes a zonas endémicas, existe el riesgo de infección por dos hongos geográficos: Histoplasma spp (histoplasmosis) y Coccidioides spp (coccidioidomicosis) los que se presentan como enfermedad pulmonar o diseminada (ver sección antagonistas de FNT $\alpha$ ).

\section{Infecciones parasitarias}

Los parásitos pueden ocasionar complicaciones infecciosas en pacientes con corticoterapia, ya sea diarrea crónica o prolongada o cuadros tisulares por reactivación de una infección latente como sucede con Toxoplasma gondii. Este agente parasitario se adquiere por la ingesta de carne contaminada inapropiadamente cocida o contacto con heces de gatos $^{45}$. La toxoplasmosis en pacientes inmunosuprimidos se presenta como un absceso del SNC con signos de focalización, convulsiones, compromiso de conciencia y a veces fiebre. Las imágenes del SNC son muy sugerentes: lesiones hipodensas con refuerzo por el medio de contraste y edema hacia los núcleos de la base. Las calcificaciones en los núcleos de la base también orientan al diagnóstico ${ }^{46}$. Se ha postulado que los raros cuadros de toxoplasmosis descritos en pacientes con colagenopatías podrían presentarse en el contexto de una reconstitución inmune con bajas dosis de corticosteroides ${ }^{47}$. La serología IgG positiva no confirma el diagnóstico, sólo indica la posibilidad de infección latente.

Una serie de protozoos intestinales tienen el potencial de afectar pacientes inmunosuprimidos por glucocorticoides $^{6,48}$. No obstante, casi no existen registros sobre enfermedades asociadas a Microsporidium, Cyclospora e Isospora belli en este grupo, más allá de los que tienen un trasplante de órgano sólido. Los reportes de pacientes afectados por Entamoeba histolytica son muy esporádicos y aparentemente asociados a exposiciones en áreas endémicas ${ }^{49-51}$. Giardia intestinalis ha sido ocasionalmente descrita en pacientes que usan corticosteroides; su presencia está más ligada a la presencia de hipogamaglobulinemia que a linfopenia o a una corticoterapia ${ }^{48}$ Cryptosporidium sp. es un agente que puede ocasionar diarrea crónica o profusa en pacientes bajo terapia corticosteroidal ${ }^{52}$.

Strongyloides es un nematode endémico en zonas tropicales y subtropicales y se adquiere por vía trans-dérmica al contactar estanques de agua dulce contaminada. Se diagnostica por la presencia de larvas en deposiciones, LBA, esputo, líquido duodenal o biopsia duodenal. Este parásito puede provocar en hospederos inmunosuprimidos cuadros de diarrea crónica, hiperinfestación (compromiso intestinal + pulmonar) o formas diseminadas (múltiples tejidos involucrados) $)^{53}$. Se sugiere descartar su presencia por métodos serológicos en pacientes que han estado expuestos a zonas endémicas, antes del uso de inmunosupresores, o en casos de eosinofilia en pacientes que han estado en estas zonas.

\section{Infecciones asociadas al uso de antagonistas del factor de necrosis tumoral $\alpha$}

El FNT- $\alpha$ es esencial para la activación de los macrófagos, la activación de los fagosomas, la diferenciación de monocitos a macrófagos, el reclutamiento de monocitos y macrófagos, la formación de granulomas y la mantención de ellos ${ }^{54}$.

Los antagonistas del FNT $\alpha$ aumentan significativamente, aunque discretamente el riesgo de infecciones graves (con hospitalización, terapia ev o deceso). En una serie observacional de pacientes con AR en el Reino Unido, el riesgo fue $20 \%$ superior en comparación al grupo de pacientes que reciben terapias con agentes modificantes de enfermedades tradicionales ${ }^{55}$. La tasa fue de 42 eventos graves por 1.000 pacientes-años en el grupo TNF $\alpha$ versus 32 por 1.000-año en el grupo con terapia convencional. El riesgo no fue diferente entre las tres moléculas incluidas 


\section{Infectología al Día}

en el registro: infliximab (Remicade ${ }^{\circledR}$ Jansen-Cilag), adalimumab (Humira ${ }^{\circledR}$ Abbott Laboratories) o etanercept (Enbrel ${ }^{\circledR}$ Wyeth-Pfizer) y fue significativamente superior al riesgo de infecciones graves en el grupo convencional sólo para los primeros seis meses de uso (OR 1,8; 1,2-2,6 $)^{55}$. En un registro francés, infliximab y adalimumab aparecen como factores independientes en el desarrollo de infecciones oportunistas en pacientes tratados con estas terapias, junto a otros factores como uso de corticosteroides en dosis equivalente a prednisona $\geq 10 \mathrm{mg}$ /día o haber recibido bolos de corticosteroides en el año previo ${ }^{3}$. La tasa de incidencia de infecciones oportunistas es elevada llegando a valores superiores a 150 por 100.000 pacientes-año ${ }^{3}$. Debido a la importancia pivotal del FNT $\alpha$ en la formación de granulomas y en la eliminación de patógenos intracelulares, las infecciones observadas en pacientes bajo este tipo de terapias están asociadas a ciertos agentes microbianos (Tabla 2).

Además, se ha reportado una mayor incidencia de infecciones pulmonares y de piel y tejidos blandos ${ }^{56-58}$. En el mundo real, muchos pacientes son tratados además con corticosteroides y ambos factores aparecen concurriendo en estas infecciones.

Legionella pneumophila es un patógeno intracelular que se asocia a cuadros de neumonía adquirida en la comunidad. La frecuencia de esta infección en pacientes con anti TNF $\alpha$, se estima unas 16 a 21 veces superior (33 a 42 por 100.000) a la registrada en la población general (2 por 100.000) y muchos pacientes han recibido concomitantemente corticosteroides aunque a una dosis baja $(<15 \mathrm{mg} / \text { día de prednisona equivalente })^{59}$.

En pacientes que reciben bloqueadores de FNT $\alpha$ se han descrito también infecciones por otros dos agentes intracelulares: L. monocytogenes y especies zoonóticas del género Salmonella ${ }^{3,58,60-62}$. El cuadro clínico dominante en el caso de listeriosis corresponde a infecciones del SNC, las que tienen una alta letalidad ${ }^{60}$. En ocasiones se han descrito cuadros de $\operatorname{artritis}^{58}$. Las salmonelosis zoonóticas se presentan como cuadros de diarrea, a veces asociados con artritis ${ }^{58}$.

Los bloqueadores del FNT $\alpha$ se asocian a un aumento de incidencia de tres enfermedades granulomatosas: $\mathrm{TBC}$, histoplasmosis y coccidioidomicosis. En algunas series este riesgo ha sido más importante con infliximab o adalimumab respecto a etarnecept ${ }^{61,62}$ pero para el caso de TBC, otras series no han encontrado diferencias entre los tres tipos de moléculas ${ }^{63}$. La incidencia de TBC puede alcanzar cifras muy elevadas en países con tasas endémicas como España con valores superiores a 400 casos por 100.000 pacientes-año en ausencia de programas de prevención ${ }^{63}$. Los cuadros de TBC incluyen formas diseminadas o extrapulmonares ${ }^{62}$.

Los cuadros de histoplasmosis se presentan en personas expuestas a zonas endémicas (no en Chile) y se expresan como neumonía o formas diseminadas ${ }^{64}$. Las zonas de riesgo corresponden a regiones húmedas tropicales o subtropicales y la tasa en expuestos a infliximab es cercana a los 19 casos por 100.000 pacientes-año ${ }^{62}$. El riesgo parece muy inferior en los usuarios de etarnecept ( 3 por 100.000 pacientes-año). Los pacientes acusan fiebre prolongada, síntomas respiratorios y un alto porcentaje evoluciona con ingreso a UCI por falla respiratoria y shock. Se requiere una alta sospecha para plantear el diagnóstico, la que es aplicable en pacientes que han vivido o visitado zonas endémicas. La presencia de fiebre prolongada, hepatoesplenomegalia, adenopatías extra-pulmonares, lesiones cutáneas u orales, masas suprarrenales o intestinales, obstrucción intestinal o hemorragia digestiva o la existencia de lesiones endoscópicas digestivas permiten la sospecha. El hemograma demuestra leucopenia, trombocitopenia y existe alzas de transaminasas hepáticas. El diagnóstico puede lograrse mediante hemocultivos para hongos, cultivo para hongos en el LBA (baja sensibilidad), detección de antígeno urinario específico, antigenemia o pruebas serológicas (estas tres últimas no disponibles en Chile).

Coccidiodocimosis es otra enfermedad granulomatosa que se observa en personas residentes en zonas áridas en América. La tasa de coccidiodimicosis en pacientes sometidos a bloqueadores del FNT $\alpha$ es aproximadamente 6 por 100.000 pacientes-año, notoriamente inferior a lo observado con TBC y principalmente asociado a infliximab $^{62,65}$. Al igual que en el caso de histoplasmosis, este riesgo se manifiesta como neumonía o enfermedad diseminada con fiebre, tos y decaimiento ${ }^{65}$. Los pacientes pueden tener una rápida progresión radiológica, falla respiratoria y diseminación a piel, articulaciones o meninges. El diagnóstico puede ser efectuado por el hallazgo de esférulas características en un estudio histológico, cultivo o pruebas serológicas (no disponibles en Chile). El riesgo

Tabla 2. Microorganismos y cuadros clínicos en pacientes que reciben terapias biológicas con bloqueadores del factor de necrosis tumoral $\alpha$

\begin{tabular}{ll} 
Agente o sitio & Manifestaciones clínicas características \\
$\begin{array}{l}\text { Bacterias intracelulares } \\
\text { Legionella pneumophila }\end{array}$ & Neumonía \\
Sisteria monocytogenes & Bacteriemia, infecciones del SNC, artritis \\
Virus & Diarrea, artritis \\
Varicela-zoster & \\
Virus de la hepatitis B & Herpes zoster (HZ) diseminado, HZ oftálmico \\
Infecciones granulomatosas & Reactivación de hepatitis (al retirar terapia) \\
Mycobacterium tuberculosis & \\
Histoplasmosis & Formas pulmonares y extrapulmonares \\
Coccidiodomicosis & Neumonía, cuadros diseminados \\
Sitio & Neumonía, cuadros diseminados \\
Pulmón & \\
Piel y tejidos blandos & Mayor incidencia de neumonía \\
\hline
\end{tabular}


de recaídas es elevado en aquellos pacientes que desarrollan enfermedad activa luego del tratamiento antifúngico.

El uso de infliximab o adalimumab aumenta el riesgo de reactivación del virus varicela-zoster en la forma de herpes zoster en $82 \%$ respecto a los medicamentos convencionales en el manejo de pacientes con AR (incidencia 11,1 eventos por 1.000 pacientes años versus 5,6), especialmente de tipo diseminado (varios dermatomas) u oftálmico. Otros factores independientes involucrados corresponden a una mayor edad, uso de corticosteroides ( $\geq 10 \mathrm{mg} /$ día prednisona equivalente) y grado de actividad de la enfermedad ${ }^{4}$. Etanercept no aparece asociado a un mayor riesgo.

Asimismo, el retiro de la terapia con bloqueadores del FNT $\alpha$ se asocia a reactivaciones de pacientes con hepatitis $\mathrm{B}$ crónica, a veces con un desenlace fatal ${ }^{66}$. Este riesgo no se observa en casos de hepatitis por $\mathrm{VHC}^{61}$.

Prevención de infecciones asociadas a uso de corticosteroides o bloqueadores de FNT $\alpha$

La prevención de infecciones asociadas al uso de corticosteroides o de FNT $\alpha$ se fundamenta en seis grupos de medidas generales más un conjunto adicional de medidas específicas según se cumplan o no ciertas condiciones en algunos pacientes. Muchas de estas medidas están basadas en el sentido común y son de fácil adopción y abarcan aspectos sobre exposición a fármacos inmunosupresores, seguridad en el consumo de agua y alimentos, exposición a mascotas, reducir el contacto con pacientes potencialmente enfermos y protección ambiental (Tablas 3 a 8). En el caso de pacientes en corticoterapia, el uso de la mínima dosis posible, idealmente bajo el umbral de infecciones oportunistas y su uso en días alternos permite reducir el riesgo de estas infecciones. Aunque, los esquemas en días alternos no pueden ser aplicados en todos los pacientes con patologías autoinmunes y podrían tener un problema de adherencia, su uso permite mantener sin supresión el eje hipotálamo-pituitaria-suprarrenal, mantener niveles circulantes adecuados de linfocitos, una respuesta adecuada en la prueba de hipersensibilidad retardada, una adecuada migración de neutrófilos a los sitios de infección y menores tasas de desarrollo de diabetes mellitus, hiperlipidemia, hipertensión arterial o manifestaciones psiquiátricas. Además, en varias experiencias, el esquema en días alternos se ha asociado a una reducción en la tasa de infecciones ${ }^{67-72}$. El control del tabaquismo es necesario

\begin{tabular}{|c|c|}
\hline Medidas generales & Objetivo \\
\hline $\begin{array}{l}\text { Disminuir exposición a fármacos } \\
\text { inmunosupresores }\end{array}$ & Disminuir dosis diaria de corticosteroides al mínimo posible y usar esquemas en días alternos. \\
\hline $\begin{array}{l}\text { Consumo de agua y alimentos } \\
\text { seguros }\end{array}$ & $\begin{array}{l}\text { Disminuir el riesgo de infecciones por Salmonella, Listeria u otros patógenos bacterianos o parásitos intestinales como Cyclospora o } \\
\text { Cryptosporidium }\end{array}$ \\
\hline Protección ambiental y laboral & Control sobre el tabaquismo, exposición a hongos ambientales y a pacientes con cuadros virales respiratorios o tuberculosis \\
\hline $\begin{array}{l}\text { Contacto con personas afectadas } \\
\text { por enfermedades contagiosas }\end{array}$ & Disminuir la exposición a pacientes con exantemas virales, infecciones virales respiratorias, tuberculosis o herpes labial \\
\hline Contacto con mascotas & Minimizar el riesgo de infecciones por T. gondii, tiñas, enfermedad por arañazo de gato, salmonelosis y otras condiciones. \\
\hline Vacunas & Aumentar la resistencia ante enfermedades inmunoprevenibles como influenza, infecciones invasoras por $S$. pneumoniae, y hepatitis B. \\
\hline
\end{tabular}

Tabla 4. Consumo de agua y alimentos seguros

- Consumir sólo agua potable o embotellada

- Evitar el consumo de huevos crudos o parcialmente cocidos tales como huevos a la copa, mayonesa o merengue casero

- Evitar el consumo de carne inadecuadamente cocida, mariscos crudos o leche no pasteurizada

- Las verduras y frutas deben ser rigurosamente lavadas antes del consumo

- La preparación de los alimentos debe ser higiénica evitando el contacto cruzado entre productos crudos y la comida ya preparada

- Las comidas frías preparadas deben ser recalentadas, al igual que los quesos blandos, antes de ser consumidos

- Evitar el consumo de frutas desecadas no envasadas al vacío tales como almendras, nueces, pasas y maní

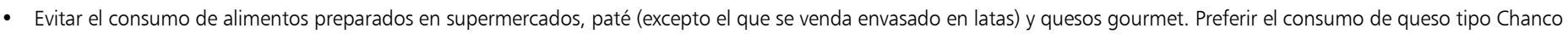
o Gauda totalmente derretido o pasteurizados 


\section{Infectología al Día}

Tabla 5. Protección ambiental y laboral

- Suspender el tabaquismo activo y pasivo y la exposición a fuentes de contaminación intra-domiciliaria

- Minimizar el uso de medios de transporte colectivo con espacios cerrados o en hora punta

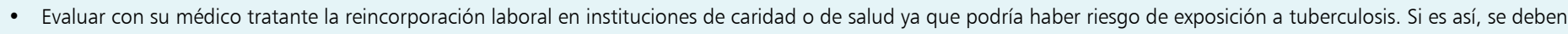
analizar las precauciones necesarias o el cambio de funciones

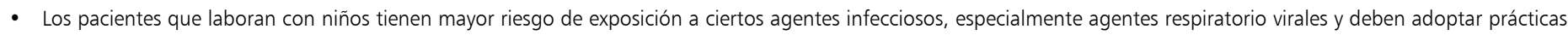
higiénicas rigurosas

- No ingerir aguas estancadas, de vertientes o lagunas

- Consultar con el médico tratante antes de efectuar viajes a zonas tropicales

por un mayor riesgo de TBC, neumonía e infecciones virales respiratorias graves.

Existen recomendaciones específicas sobre el manejo de mascotas por pacientes inmunosuprimidos editadas en el país ${ }^{73}$. Estas medidas son importantes de adoptar ya que los pacientes inmunosuprimidos tienen con frecuencia mascotas, las que tienen un bajo porcentaje de control veterinario, son portadoras de condiciones de riesgo para el paciente y los pacientes tienen conductas con ellas que los exponen a diferentes enfermedades graves ${ }^{73}$.

\section{Vacuna influenza en pacientes que reciben} antagonistas del FNTa o corticosteroides

La respuesta inmune a la vacuna influenza está conservada en pacientes con AR que reciben bloqueadores de FNT $\alpha$ y es comparable a la de población sana. Cerca de $66 \%$ logra una seroconversión protectora, no estadísticamente diferente al $78 \%$ observado en una población sana de control ${ }^{74}$. En contraste, los pacientes con AR tratados con metotrexato revelan una respuesta inmune significativamente inferior (56\% de seroprotección) al grupo control. En el estudio señalado, la dosis diaria promedio de los pacientes con bloqueadores del FNT $\alpha$ fue $7 \mathrm{mg}$ de prednisona. En contraste, los pacientes con espondiloartritis tratados con infliximab o adalimumab tuvieron una respuesta inmune inferior (64\% seroprotección) respecto a controles sanos pero no si recibieron etanercept (86\% seroprotección). En un trabajo similar que incluyó mayoritariamente pacientes con AR, la tasa de seroprotección alcanzada en usuarios de bloqueadores de FNT $\alpha$, fue elevada, superando el 80 a 94\% según el tipo viral considerado ${ }^{75}$. Al igual que en el estudio ya comentado, la dosis diaria promedio de prednisona era de $7 \mathrm{mg}$ y $20 \%$ de los pacientes estaban recibiendo este compuesto. Ambos trabajos indican que la vacuna influenza no tiene restricciones para ser indicada en pacientes con terapias biológicas, siempre y cuando no sean usuarios de altas dosis de corticosteroides. Para aquellos pacientes que reciben glucocorticoides, incluyendo aquellos con dosis $>$ $10 \mathrm{mg} /$ día de prednisona (o equivalente), la inmunización
Tabla 6. Contacto con personas afectadas por enfermedades contagiosas

Evitar las visitas de personas con las siguientes condiciones

- Afectadas por cuadros "tipo gripe" o influenza. Si ello fuera imprescindible, las visitas o familiares afectados, deben usar mascarilla quirúrgica desechable bien ajustada a la cara y nariz y cambiarla cada vez que ésta se encuentre humedecida. Además, deberán lavarse las manos con frecuencia y evitar tocar al afectado

- Personas afectadas con rubéola, varicela o infecciones virales con exantema

- Personas afectadas por tuberculosis pulmonar

- Personas afectadas por herpes labial

\section{Tabla 7. Contacto con mascotas}

- Evitar la adquisición, mantención y/o manipulación de mascotas

- Si ello no es posible, las mascotas deben estar bajo control veterinario

- No se recomienda, por motivo alguno, la tenencia de aves, reptiles, hurones, peces y conejos

- Se debe evitar la adquisición de animales menores de 6 meses de edad ( $<1$ año en caso de gatos) y la adopción de animales vagabundos

- Adoptar prácticas rigurosas de higiene cada vez que se manipula una mascota

- Evitar manipular sus excretas

- En el caso de los gatos, la alimentación no debe incluir alimentos parcialmente cocidos o crudos y deben ser mantenidos en el domicilio para evitar actividades de caza

- La presencia de vectores como pulgas y ectoparásitos debe ser controlada

Tabla 8. Vacunas generales en el paciente usuario de corticosteroides o de bloqueadores del factor de necrosis tumoral $\alpha$

- Recibir anualmente la vacuna antigripal antes del comienzo de la temporada de influenza. Se aconseja recibir esta vacuna en el mes de marzo o, a más tardar, en el mes de abril

- Los familiares que viven o visitan rutinariamente al paciente, deben recibir anualmente la vacuna antigripal para evitar el contagio hacia el paciente

- Asegurar que la vacuna BCG fue recibida de acuerdo a programa

- Vacuna antineumocóccica. Aplicarla con la menor dosis de corticosteroides posible.

- Aplicar vacuna anti-hepatitis B en pacientes susceptibles (seronegativos) que recibirán bloqueadores del FNT 
contra influenza logra tasas de sero-protección cercanas a $80 \%$ para un sinnúmero de condiciones autoinmunes ${ }^{76}$. Aunque la vacunación contra influenza puede asociarse a activación clínica de la enfermedad de base, ello ocurre en forma infrecuente ${ }^{76}$.

Vacuna antineumocóccica en pacientes que reciben antagonistas del FNTa o corticosteroides

Tanto la vacuna heptavalente conjugada antineumocóccica como la 23-valente polisacárida, son capaces de inducir una respuesta inmune similar en pacientes con AR que reciben antagonistas del FNT $\alpha$ y esta respuesta es similar a controles sanos cuando es medida a las pocas semanas de vacunación (cerca de $55 \%$ en pacientes con terapias biológicas o en controles sanos comparativos). No se han detectado diferencias de acuerdo al antagonista utilizado en estos pacientes. La respuesta es menor en pacientes que reciben metotrexato o metotrexato con antagonistas del FNT $\alpha$ y en pacientes de edad mayor ${ }^{77-79}$. Al seguimiento a las seis semanas, sólo $20 \%$ de los pacientes bajo terapia con metotrexato tienen una respuesta inmune. Tanto los pacientes bajo el efecto de bloqueadores del FNT $\alpha$, como aquellos que reciben metotrexato, disminuyen notoriamente los niveles de anticuerpos logrados al inicio con vacuna conjugada luego de un año y medio de seguimiento, indicando serias limitaciones para obtener un efecto protector ${ }^{80}$.

Para pacientes que reciben corticosteroides $\mathrm{u}$ otros fármacos inmunosupresores, la respuesta a la vacuna 23-valente polisacárida es inferior respecto a controles sanos y restringida a algunos serotipos ${ }^{81}$. La vacunación contra S. pneumoniae no se acompaña de una activación de la enfermedad basal ${ }^{81}$. La vacuna conjugada 13 -valente ofrece protección para aproximadamente 55 a 77\% de los serotipos circulantes en el país y la vacuna polisacárida 23 valente para 77 a $95 \%$ de los serotipos circulantes en el país ${ }^{82}$.

Los datos entregados indican que ambas vacunas antineumocóccicas tienen problemas de inmunogenicidad y/o cobertura y no se puede establecer aún una recomendación definitiva sobre el tipo de vacuna preferente para este tipo de pacientes. No se recomienda revacunar con la vacuna 23-valente polisacárida ya que la exposición repetida a polisacáridos bacterianos produce respuestas inmunes de menor cuantía que la inicial (hiporespuesta o tolerancia inmune $)^{83-85}$. Las ventajas del uso combinado de vacunas conjugadas y polisacaráridas para $S$. pneumoniae y el orden secuencial de su aplicación aún no han sido establecidos para la población adulta y los datos disponibles apuntan a serias limitaciones en la respuesta inmune ${ }^{86,87}$.

De manera independiente a las consideraciones relacionadas con una menor respuesta inmunogénica en usuarios de corticosteroides o antagonistas del FNT, se recomienda el uso de ambas vacunas por el potencial beneficio que ello representa, atendiendo a la gran carga de enfermedad que representan las infecciones respiratorias en estos pacientes. En una cohorte de pacientes con AR en Australia, se pudo observar que la incorporación sistemática de la vacuna contra influenza y $S$. pneumoniae polisacárida 23 valente, junto a medidas tales como la minimización de corticoterapia a largo plazo, la suspensión de medicamentos modificantes de la enfermedad en caso de ingreso por neumonía, el uso de ácido folínico ante leucopenia $<5.000 / \mathrm{mm}^{3}$ (en usuarios de metotrexato) y de estimuladores de colonias ante neutropenias $<500 /$ $\mathrm{mm}^{3}$, permitieron reducir el número de ingresos por este problema y la mortalidad en los ingresos ${ }^{88}$.

Hay vacunas atenuadas que los pacientes con corticosteroides no pueden recibir tales como anti-polio oral, fiebre amarilla, antitífica oral, BCG, trivírica, varicela y rotavirus.

Los pacientes con AR tienen un mayor riesgo de infecciones aun sin terapias inmunosupresoras o biológicas.

\section{Prevención de riesgos especificos}

La prevención de infecciones específicas difiere según si el paciente recibe antagonistas del FNT $\alpha$ o corticosteroides en dosis inmunosupresoras. Para el primer caso, el riesgo está centrado en la posibilidad de una reactivación de TBC por infección latente o una reactivación de una infección crónica por virus de hepatitis B. En el caso de usuarios de corticosteroides, para pacientes en países no tropicales, la prevención se centra igualmente en TBC y en el riesgo de neumonía por $P$. jiroveci.

Evaluación del riesgo de tuberculosis y su prevención: La infección latente por TBC es de alta prevalencia, afectando a aproximadamente un tercio de la población mundial. Sólo cerca de $10 \%$ de los que tienen infección latente presentan una reactivación a lo largo de su vida evidenciando posteriormente TBC pulmonar o extrapulmonar. Este porcentaje de reactivación es mayor en pacientes inmunosuprimidos ya sea por infección por VIH/ SIDA, trasplante, uso de corticosteroides o de antagonistas del FNT $\alpha$ y además, la TBC en esta población es de mayor gravedad, extensión o complejidad terapéutica. Existen tres formas conocidas para averiguar si un paciente tiene una infección por TBC latente y que corresponden a:

- Hallazgo de lesiones apicales residuales en la radiografía de tórax,

- Historia de exposición reciente o remota a un paciente con TBC pulmonar bacilífera o

- Prueba positiva para un test de tuberculina positiva o de un ensayo de liberación de gama-interferón (interferon-gamma release assays: IGRAs) con antígenos específicos de M. tuberculosis.

Cualquiera de ellas por separado, en ausencia de 
síntomas sugerentes de actividad clínica, indica una infección latente por M. tuberculosis y la necesidad de aplicar quimioprofilaxis con isoniazida.

El riesgo de progresión de infección latente a $\mathrm{TBC}$ activa en pacientes con lesiones residuales pulmonares ha sido documentado en diferentes tipos de pacientes inmunocompetentes, con co-morbilidades médicas o inmunosuprimidos ${ }^{89}$. Este riesgo es proporcionalmente mayor en pacientes con una prueba de tuberculina basal de mayor intensidad ( $\geq 15 \mathrm{~mm}$ versus $10-14 \mathrm{~mm}$ versus $<10$ $\mathrm{mm}$ ) y en personas más jóvenes puesto que tienen más año de sobrevida para expresar este riesgo (Figura 1) ${ }^{89}$.

Asimismo, el riesgo de TBC activa en contactos familiares (no inmunosuprimidos) de pacientes bacilíferos pulmonares es relevante y proporcional a la magnitud de la prueba de tuberculina, lo que subraya el rol de haber tenido contacto con pacientes bacilíferos en el riesgo de $\mathrm{TBC}^{89}$.

Las pruebas basadas en IGRAs tienen alta especificidad respecto a la prueba de tuberculina porque sólo emplean antígenos específicos de $M$. tuberculosis y no aquellos comunes entre esta especie y micobacterias atípicas o el bacilo de Calmette-Guerin de la vacuna BCG. Una prueba de tuberculina positiva puede indicar infección por M. tuberculosis, vacuna BCG previa o exposición a micobacterias ambientales. En contraste, estas últimas dos condiciones no contaminan la lectura de una prueba IGRA positiva, determinando una mayor especificidad ${ }^{90}$. Las pruebas IGRAs tienen la ventaja de que requieren una sola visita al laboratorio pero son de mayor costo que la prueba PPD. Ni las pruebas IGRAs ni la de tuberculina diferencias infección latente de enfermedad clínica.

Se dispone de dos alternativas para efectuar las pruebas IGRAs: QuantiFERON Gold ${ }^{\circledR}$ y T-Spot ${ }^{\circledR}$ (Elispot). Ambas trabajan con las células mononucleares extraídas del paciente que son expuestas a péptidos específicos de M. tuberculosis por algunas horas. Tanto QuantiFERON Gold ${ }^{\circledR}$ como T-Spot $\AA$ ofrecen una celda control donde los monocitos son estimulados con mitógenos para descartar un freno en la respuesta de los linfocitos a la liberación de interferón. La ausencia de estimulación de la liberación interferón- $\gamma$ en la celda con mitógenos implica que los linfocitos están bloqueados para generar esta respuesta lo que se conoce como un resultado indeterminado. Si la prueba es indeterminada y además no hay liberación de interferón a la exposición ante antígenos de $M$. tuberculosis no se puede concluir que la prueba IGRA es negativa ya que no se asegura que los linfocitos tuvieron la oportunidad de generar una respuesta adecuada ${ }^{90,91}$.

Los corticosteroides y otros inmunosupresores aumentan el porcentaje de pruebas IGRAs con un valor indeterminado. En pacientes que reciben estos compuestos, especialmente en combinación, el porcentaje de pruebas indeterminadas se acerca a $30 \%, 10$ veces superior a lo observado en la población general ${ }^{11,92}$. La probabilidad de una prueba indeterminada es mayor si el paciente recibe $>10$ a $15 \mathrm{mg}$ diarios de dosis equivalente de predniso$\mathrm{na}^{92,93}$ Los corticosteroides también tornan negativa la prueba de tuberculina ${ }^{93}$.

Los antecedentes entregados resaltan la importancia de detectar pacientes en riesgo de reactivación de TBC por infección latente previa, tanto si reciben dosis inmunosupresoras de corticosteroides como antagonistas del FNT $\alpha$. La importancia de este riesgo ha llevado a incluir protocolos de evaluación de pacientes con infección latente por $M$. tuberculosis, que están basados en general en la triple consideración de: historia de exposición a pacientes bacilíferos; lesiones residuales apicales en la radiografía de tórax; y prueba IGRA o de tuberculina positiva, ameritando cualquiera de ellas por separado, una quimioprofilaxis para $\mathrm{TBC}^{94,95}$.

El uso conjunto de estas evaluaciones con quimioprofilaxis a grupos seleccionados, ha permitido reducir el riesgo de TBC en usuarios de antagonistas del FNT $\alpha$ en $78 \%$ respecto a cifras anteriores a la adopción de esta estrategia ${ }^{95}$. Más aún, la persistencia del riesgo ha estado ligada a la baja adherencia a estas recomendaciones ${ }^{63}$. En caso de usar la prueba de tuberculina, se recomienda una segunda prueba una semana después si la primera es negativa debido a la posibilidad de un falso negativo por no lograr estimularse la memoria inmune con la primera prueba $^{63,95}$.

El uso de pruebas IGRAs o tuberculina depende de las preferencias del médico tratante, disponibilidad, costo y existencia de guías nacionales. Se reconoce que las

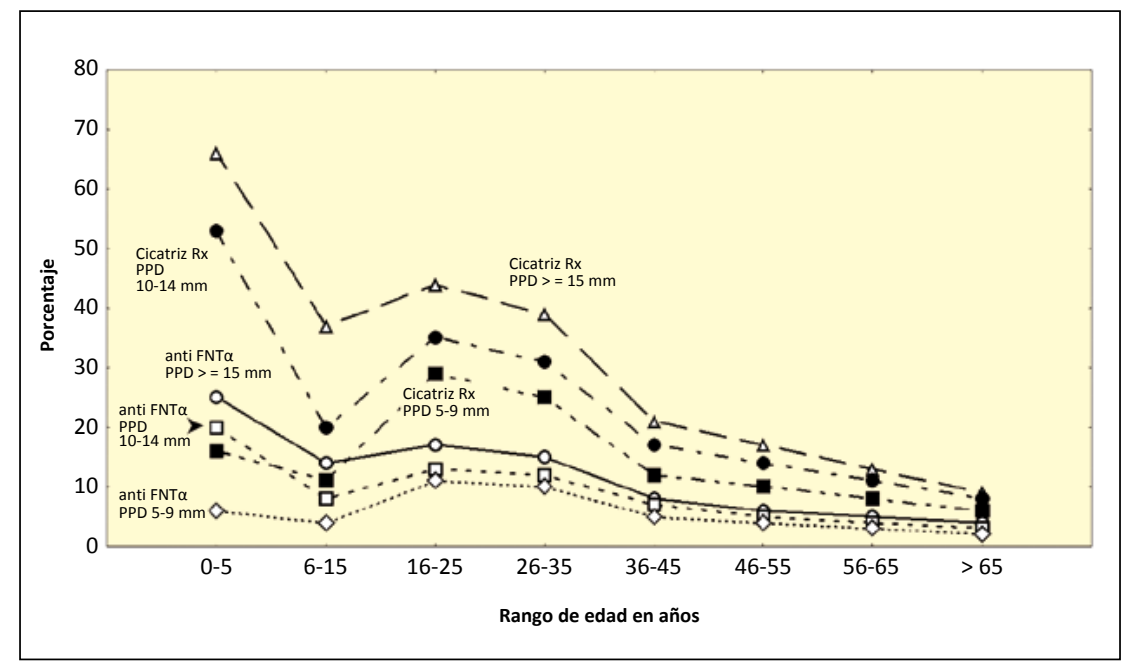

Figura 1. Riesgo de tuberculosis-TBC activa durante toda la vida en diferentes situaciones. En la figura se presentan los riesgos ante diferentes valores de la prueba de tuberculina (PPD) con presencia de cicatriz radiológica de TBC (cicatriz Rx) o uso de bloqueadores del FNT $\alpha$ (anti-FNT $\alpha$ ). Se puede observar que a mayor valor de la prueba de tuberculina, el riesgo de TBC activa es mayor para cualquier tipo de exposición. Datos adaptados de referencia 89. 
Tabla 9. Componentes anamnésticos a averiguar en pacientes que recibirán terapia inmunosupresora con corticosteroides o antagonistas del factor de necrosis tumoral $\alpha$

\begin{tabular}{|c|c|}
\hline Componente & Comentarios \\
\hline $\begin{array}{l}\text { Esquema de inmunosupresión } \\
\text { que será usado y dosis diaria de } \\
\text { corticosteroides }\end{array}$ & $\begin{array}{l}\text { Identifica riesgos específicos, dosis umbral y asociación de inmu- } \\
\text { nosupresores los que modifican el riesgo de infecciones }\end{array}$ \\
\hline Tabaquismo, EPOC & $\begin{array}{l}\text { Identifica pacientes con mayor riesgo de complicaciones pul- } \\
\text { monares por infecciones virales o bacterianas, incluyendo TBC }\end{array}$ \\
\hline Alcohol & $\begin{array}{l}\text { Aumenta riesgo de hepatotoxicidad en caso de usarse isoniazida } \\
\text { o metotrexato }\end{array}$ \\
\hline $\begin{array}{l}\text { Contacto con paciente bacilífero } \\
\text { pulmonar }\end{array}$ & Aumenta riesgo de TBC activa \\
\hline Hepatitis virales & Aumenta el riesgo de reactivación en caso de hepatitis B crónica \\
\hline $\begin{array}{l}\text { Herpes simplex, varicela o herpes } \\
\text { zoster }\end{array}$ & Aumenta el riesgo de reactivación y formas diseminadas \\
\hline $\begin{array}{l}\text { Residencia o viajes a zonas de } \\
\text { riesgo }\end{array}$ & $\begin{array}{l}\text { Aumenta el riesgo de infecciones por hongos geográficos y } \\
\text { ciertas parasitosis }\end{array}$ \\
\hline Tipo de alimentos & $\begin{array}{l}\text { Permite identificar el riesgo de listeriosis, salmonelosis, toxoplas- } \\
\text { mosis, enfermedades parasitarias intestinales, etc. }\end{array}$ \\
\hline Mascotas & $\begin{array}{l}\text { Permite identificar los riesgos potenciales y nivel de cuidado que } \\
\text { tiene la mascota }\end{array}$ \\
\hline Vacunas & $\begin{array}{l}\text { Permite evaluar posible protección ante influenza, enfermedad } \\
\text { neumocóccica invasora, hepatitis B u otras condiciones }\end{array}$ \\
\hline
\end{tabular}

pruebas IGRAs tienen mayor especificidad y el potencial de exponer a menos pacientes innecesariamente a quimioprofilaxis respecto a la prueba de tuberculina. En caso de aplicarse la prueba de tuberculina, debe ser aplicada una segunda vez en caso de un primer resultado negativo ${ }^{63}$. El valor de corte en pacientes inmunosuprimidos es $>5 \mathrm{~mm}$.

La duración de la quimioprofilaxis con isoniazida en pacientes inmunosuprimidos es mayor que en pacientes inmunocompetentes atendiendo a que su eficacia protectora es mejor a medida que esta profilaxis se prolonga. La eficacia protectora es cercana a $75 \%$ para profilaxis de un año de duración, de $65 \%$ para esquemas de 6 meses y de sólo $21 \%$ para esquemas de 3 meses $^{96}$. La mayor parte recomienda esquemas profilácticos durante 9 meses ${ }^{95,97}$. El riesgo de hepatitis por isoniazida se concentra en los primeros 9 meses y alcanza los 5 casos por 1.000 expuestos en caso de pacientes generales. La tolerancia a isoniazida en series de pacientes que reciben simultáneamente metotrexato ha sido favorable en algunas series, sólo $11 \%$ de pacientes con aumento leve y transitorio de las transaminasas hepáticas ${ }^{97}$. Otras series han reportado una mayor tasa de efectos adversos hepáticos ${ }^{98}$. Durante la administración de isoniazida el paciente no puede consumir alcohol y debe recibir piridoxina para evitar la polineuropatía por este compuesto. Es importante el control periódico de las transaminasas hepáticas. Isoniazida se asocia a riesgo (bajo) de LES inducido por fármacos $(<1 \%)$ y esta condición debe ser considerada si aparecen artralgias o mialgias, serositis o fiebre luego de su inicio. Puede presentar anticuerpos anti-histonas pero, a diferencia del LES, no se asocia a anticuerpos anti $\mathrm{ADN}$ de doble cadena ${ }^{99}$. De ocurrir, se debe suspender la isoniazida y aplicar quimioprofilaxis complementaria con rifampicina + pirazinamida $^{100}$.

Riesgo de reactivación de hepatitis $B$. Como se comentó anteriormente, se plantea este riesgo en paciente portadores de hepatitis crónica por VHB que recibirán bloqueadores del $\mathrm{FNT} \alpha^{65}$. El uso de fármacos antivirales para VHB disminuye efectivamente este riesgo si es que el paciente no está recibiendo ya un tratamiento por hepatitis crónica ${ }^{101}$. Se prefiere el uso de fármacos con alta barrera de resistencia tales como tenofovir o entecavir.

Riesgo de reactivación de VZV. A pesar de existir un riesgo de reactivación de VZV como herpes zoster diseminado u oftálmico, la vacuna anti-zoster (cepa atenuada) está contraindicada en pacientes con dosis inmunosupresoras de corticosteroides y durante el uso de anti FNT $\alpha$.

Prevención de infecciones por P. jiroveci. No existen estudios controlados que directamente hayan evaluado la eficacia de la profilaxis de neumonía por P. jiroveci en usuarios de corticosteroides. La eficacia de un esquema diario con cotrimoxazol es muy alta en pacientes oncohematológicos y en pacientes con trasplante de órganos sólidos (> 90\% eficacia) y además reduce el riesgo de mortalidad por esta causa (eficacia $>80 \%{ }^{102}$. Las dosis en los esquemas ha sido variable con una tendencia central a usar una tableta de cotrimoxazol forte $(800 / 160$ $\mathrm{mg}$ de sulfametoxazol/trimetoprim) al día. De acuerdo a la evidencia y modelos estadísticos, la quimioprofilaxis debe ser considerada en casos con dosis diaria equivalente $>30 \mathrm{mg} /$ día junto a otros fármacos inmunosupresores y linfopenia post inicio de corticosteroides ${ }^{40-42}$.

\section{Evaluación general del paciente antes de iniciar la inmunosupresión}

En la Tabla 9 se presentan los componentes de una evaluación anamnéstica necesaria en pacientes que recibirán corticosteroides en dosis inmunosupresoras y/o terapias biológicas con antagonistas del FNT $\alpha$. Los exámenes que pueden ser considerados en estos pacientes se indican en la Tabla 10.

\section{Resumen de medidas preventivas}

En la Figura 2 se sintetizan las principales medidas preventivas para pacientes bajo terapia corticosteroidal o antagonistas del FNT $\alpha$. Si un paciente recibe ambos compuestos, se deben considerar las medidas para el subgrupo con corticosteroides. Muchos de los riesgos en estos pacientes no pueden ser anulados y por ello es importante educarlos sobre la consulta precoz con su equipo tratante para un diagnóstico y tratamiento oportunos.

Se recomienda quimioprofilaxis para $\mathrm{TBC}$ al menos en 
pacientes con lesiones apicales residuales en la radiografía de tórax o historia de contacto con un paciente bacilífero pulmonar o una prueba IGRA o de tuberculina positiva. Si la primera prueba de tuberculina es negativa, se debe efectuar una segunda prueba una semana después para descartar una prueba falsamente negativa. El médico tratante podría considerar otros factores independientes a los señalados para indicar quimioprofilaxis para TBC, tales como enfermedad renal avanzada, desnutrición, diabetes mellitus pobremente controlada, etc.

La quimioprofilaxis con isoniazida debe extenderse por al menos 9 meses, con control periódico de transaminasas hepáticas, uso concomitante de vitamina $\mathrm{B}_{6}$ oral (50-100 $\mathrm{mg} /$ día) y evitar el consumo de alcohol.

La quimioprofilaxis para $P$. jiroveci puede considerarse en pacientes que reciben $\geq 30 \mathrm{mg}$ de prednisona al día, o con cifras menores en caso de uso de otros inmunosupresores o desarrollo de linfopenia $(<1.000 / \mu \mathrm{L})$ en las primeras dos semanas de haber iniciado la corticoterapia. El compuesto habitualmente indicado es cotrimoxazol forte en dosis de una tableta diaria por 5 ó 3 veces por semana.

El manejo de un paciente con hepatitis B crónica debe ser efectuado por un especialista en la materia.

\section{Otros riesgos en pacientes reumatológicos}

El riesgo de infecciones en los pacientes reumatológicos se sobrepone a los riesgos determinados por la propia enfermedad. En el caso de la AR, hay un incremento en la mortalidad respecto a la población general en los primeros años desde el diagnóstico, atribuible a un mayor peso relativo por causas cardiovasculares, fibrosis pulmonar y linfoma ${ }^{103}$. El exceso en mortalidad aparece ligado al sexo masculino, mayor edad, menor nivel socioeconómico, pobre nivel funcional y mayor gravedad clínica, incluyendo manifestaciones extra-articulares. El mayor riesgo cardiovascular podría estar ligado al estado inflamatorio del paciente y al efecto adverso de los corticosteroides sobre el metabolismo, aunque estos últimos no aparecen ligados a un mayor riesgo de muerte ${ }^{104}$. El uso de terapias modificantes no aparece como un factor de riesgo en mortalidad pero los anti-inflamatorios no esteroidales generan muertes por hemorragia digestiva. Estos antecedentes indican que la AR per se genera o está ligada a factores patogénicos o socio-económicos, que disminuyen las posibilidades de sobrevida de estos pacientes y que se sobreponen al riesgo impuesto por algunas terapias e infecciones. Una perspectiva integrada la entrega un estudio efectuado en el Reino Unido que demuestra que los pacientes con AR que tienen mayor riesgo de hospitalizarse por infecciones respiratorias, está constituido por pacientes de sexo masculino, de mayor
Tabla 10. Evaluaciones de laboratorio a considerar en pacientes

que recibirán terapia inmunosupresora con corticosteroides o antagonistas del factor de necrosis tumoral $\alpha$

\section{Componente Comentarios}

Hemograma

Parte de la evaluación general. Permite evaluar el recuento basal de linfocitos antes del uso de corticosteroides

Radiografía de tórax Búsqueda de lesiones apicales residuales o calcificaciones que sugieran infección latente por tuberculosis

Pruebas hepáticas

Evalúa condición basal para el potencial uso de isoniazida o identifica pacientes con hepatitis crónica

Serologías

VIH: para identificar co-infección con inmunosupresión asociada. Marcadores de hepatitis B y C: para identificar pacientes con hepatitis crónica

Evaluación de infección latente por pruebas IGRAs o prueba de tuberculina

Identifica pacientes en riesgo. En caso de usar PPD aplicar dos pruebas si la primera es negativa

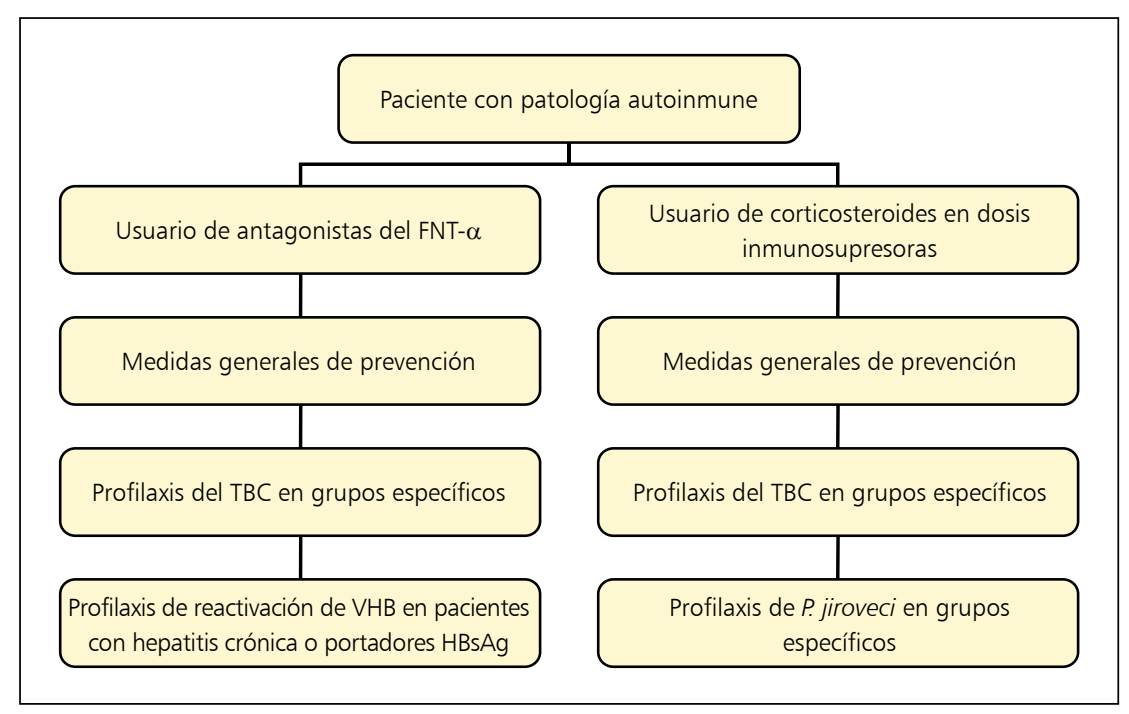

Figura 2. Resumen de medidas preventivas en pacientes con colagenopatías que usan corticosteroides o bloqueadores del factor de necrosis tumoral $\alpha$.

edad y que son usuarios de corticosteroides. En contraste, el uso de fármacos modificantes, (los que por definición no incluyen a los corticosteroides) disminuye el riesgo de hospitalización insinuando que el control de la enfermedad es beneficioso y logra antagonizar el impacto de las infecciones ${ }^{105}$. De la misma manera, en pacientes con LES, cerca de dos tercios de las causas de muerte obedecen a complicaciones de la enfermedad o su tratamiento, tales como infecciones, eventos cardiovasculares, cáncer y hemorragia gastrointestinal ${ }^{106}$. Estas causas tienden a ocurrir varios años después del diagnóstico y contribuyen a una sobrevida acortada a largo plazo ${ }^{106}$. 


\section{Resumen}

Una gran diversidad de agentes infecciosos puede afectar a los pacientes que usan corticosteroides en dosis inmunosupresoras o antagonistas del factor de necrosis tumoral $\alpha(\mathrm{FNT} \alpha)$. La lista de microorganismos participantes es más restringida en el caso de los bloqueadores del FNTa. Los agentes que se sobreponen incluyen bacterias intracelulares, Mycobacterium tuberculosis, hongos geográficos que son capaces de establecer infecciones granulomatosas, herpes zoster y reactivación de hepatitis crónica por virus de hepatitis B. Existe una dosis umbral diaria de prednisona (o equivalente), sobre la cual emergen estas infecciones oportunistas, pero el nivel de inmunosupresión parece ser más alto en el caso de Pneumocystis jiroveci o citomegalovirus. Para prevenir estas amenazas, se requiere una evaluación médica detallada antes de su prescripción para detectar riesgos potenciales y manejarlos apropiadamente. Se deben indicar medidas de prevención en cada caso, las que incluyen conductas de sentido común y en casos seleccionados, quimioprofilaxis para infección latente por tuberculosis (TBC), neumonía por $P$. jiroveci u otros requerimientos específicos. La existencia de TBC latente es probable en el caso de exposición reciente o remota a un bacilífero pulmonar, prueba de tuberculina o de liberación de interferón $\gamma$ positiva, o lesiones residuales en la radiografía de tórax. La prevención de neumonía por $P$. jiroveci se recomienda cuando se usan al menos $30 \mathrm{mg}$ de prednisona al día pero puede ser necesario a dosis menores si se aplican otros fármacos inmunosupresores concomitantes o si aparece linfopenia poco después del inicio de los corticosteroides.

\section{Referencias bibliográficas}

1.- Lionakis M S, Kontoyiannis D P. Glucocorticoids and invasive fungal infections. Lancet 2003; 362: 1828-38.

2.- $\quad$ Stuck A E, Minder C E, Frey F J. Risk of complications in patients taking glucocorticosteroids. Rev Infect Dis 1989; 11: 954-63.

3.- Salmon-Céron D, Tubach F, Lortholary O, Chosidow O, Bretagne S, Nicolas N, et al. Drug-specific risk of non-tuberculosis opportunistic infections in patients receiving anti-TNF therapy reported to the 3-year prospective French RATIO registry. Ann Rheum Dis 2011; 70: 616-23.

4.- Strangfeld A, Listing J, Herzer P, Liebhaber A, Rockwitz K, Richter C, et al. Risk of herpes zoster in patients with rheumatoid arthritis treated with anti-TNF- $\alpha$ agents. JAMA 2009; 301: 737-44.

5.- Hoes J N, Jacobs J W, Verstappen S M, Bijlsma J W, van der Heidjen G J. Adverse events of low- to medium-dose oral glucocorticoids in inflammatory diseases: a meta-analysis. Ann Rheum Dis 2009; 68: 1833-8.

6.- Klein NC, Go CH, Cunha BA. Infections associated with steroid use. Infect Dis Clin North Am 2001; 15: 423-32.

7.- de Luis A, Pigrau C, Pahissa A, Fernández F, Martínez-Vázquez J M. Infections in 96 cases of systemic lupus erythematosus. Med Clin (Barc) 1990; 94: 607-10

8.- Marcos M, Fernández Q, Soriano A Marco H. Martínez J A.AAlmela M, et al. Epidemiology and clinical outcomes of bloodstream infections among lupus patients. Lupus 2011; 20: 965-71.

9.- Chen M J, Tseng H M, Huang Y L, Hsu W N, Yeh K W, Wu T L, et al. Long-term outcome and short-term survival of patients with

systemic lupus erythematosus after bacteraemia episodes: 6-yr follow-up Rheumatology 2008; 47: 1352-7.

10.- Jacobsson G, Dashti S, Wahlberg T, Andersson R. The epidemiology of and risk factors for invasive Staphylococcus aureus infections in western Sweden. Scand J Infect Dis 2007; 39: 6-13.

11.- Fica A, Jemenao M I, Bilbao P, Ruiz G, Sakurada A, Pérez de Arce E, et al. Emergencia de infecciones por Enterococcus sp resistente a vancomicina en un hospital universitario en Chile. Rev Chilena Infectol 2007; 24: 462-71.

12.- Huang C F, Chen P L, Liu M F, Lee C C, Lee N Y, Chang C M, et al. Nontyphoidal Salmonella bacteremia in patients with connective tissue diseases. J Microbiol Immunol Infect 2012; 45: 350-5.

13.- Sedano R, Fica A, Guíñez D, Braun S, Porte L, Dabanch J, et al. Infecciones por Listeria monocytogenes. Una experiencia de 2 décadas. Rev Chilena Infectol 2013; 30 (4): 417-25.

14.- Jick S S, Lieberman E S, Rahman M U, Choi H K. Glucocorticoid use, other associated factors, and the risk of tuberculosis. Arthritis Rheum 2006; 55: 19-26.

15.- Hou C L, Tsai Y C, Chen L C, Huang J L. Tuberculosis infection in patients with systemic lupus erythematosus: pulmonary and extra-pulmonary infections compared. Clin Rheumatol 2008; 27: 557-63.

16.- McGhie 1], Fader R, Carpenter ., Brown-Elliott BA, Vasireddy R, Wallace R J Jn, Nocardia heocaldoniensis as a cause of skin and soft tissue infection. J Clin Microbiol 2012; 50: 3139-40.

17.- Naqi R, Ahsan H, Azeemuddin M. Cerebral hocardiosis. J Pak Med Assoc 2011; 61: 697-9.
18.- Leong K P, Tee N W, Yap W M, Chee T S, Koh E T. Nocardiosis in patients with systemic lupus erythematosus. J Rheumatol 2000; 27: 1306-12.

19.- Mc-Nab P, Fuentealba C, Ballesteros F, Pacheco D, Álvarez M, Dabanch J, et al. Infección por Nocardia asteroides en una paciente con lupus eritematoso sistémico. Rev Med Chile 2000; 128: 526-8.

20.- Das R, Feuerstadt P, Brandt L J. Glucocorticoids are associated with increased risk of shortterm mortality in hospitalized patients with Clostridium difficile-associated disease. Am J Gastroenterol 2010; 105: 2040-9.

21.- Blumentals W A, Arreglado A, Napalkov P, Toovey $\mathrm{S}$. Rheumatoid arthritis and the incidence of influenza and influenza-related complications: a retrospective cohort study. BMC Musculoskelet Disord 2012; 13: 158. doi: 10.1186/1471-2474-13-158.

22.- Han K, Ma H, An X, Su Y, Chen J, Lian Z, et al. Early use of glucocorticoids was a risk factor for critical disease and death from pH1N1 infection. Clin Infect Dis 2011; 53: 326-33.

23.- Lu F, Tu Y, Peng X, Wang L, Wang H, Sun Z, et al. A prospective multicentre study of mycophenolate mofetil combined with prednisolone as induction therapy in 213 patients with active lupus nephritis. Lupus 2008; 17: 622-29.

24.- Grootscholten C, Ligtenberg G, Hagen E C, van den Wall Bake A W, de Glas-Vos J W, Bijl M, et al. Azathioprine/methylprednisolone versus cyclophosphamide in proliferative lupus nephritis. A randomized controlled trial. Kidney Int 2006; 70: 732-42.

25.- Pope J E, Krizova A, Ouimet J M, Goodwin J L, Lankin M. Close association of herpes zoster reactivation and systemic lupus erythematosus (SLE) diagnosis: case-control study of patients 
with SLE or noninflammatory nusculoskeletal disorders. J Rheumatol 2004; 31: 274-9.

26.- Long J O, Wheeler C E J, Briggaman R A Varicella-like infection due to herpes simplex. Arch Dermatol 1978; 114: 406-9.

27.- Barsky G J, Weiss D, Ronan S G Chronic infection with cutaneous herpes simplex in a patient with systemic lupus erythematosus. Am J Dermopathol 1983; 5: 73-6.

28.- Kluger N, Boutboul D, Molinari E, Haroche J. Rozenberg H, Amoura Z, et al. Acute hepatitis during primary herpes simplex type 2 infection in a patient with systemic lupus erythematosus. Ann Dermatol Venereol 2007; 134 (4 Pt 1): 369-73.

29.- Yamashita M, Ishii T, Iwama N, Takahashi H. Incidence and clinical features of

cytomegalovirus infection diagnosed by cytomegalovirus pp65 antigenemia assay during high dose corticosteroid therapy for collagen vascular diseases. Clin Exp Rheumatol 2006; 24: 649-55.

30.- Sánchez Escuredo A, Grados Cànovas D, Ibernon Vilaró M, López Álvarez D, Moreno de Vega Lomo V, Navarro Díaz M, et al. Cytomegalovirus colitis. Nefrología 2011; 31: 119-20.

31.- Tokunaga N, Sadahiro S, Kise Y, Suzuki T, Mukai M, Yasuda S, et al. Gastrointestinal cytomegalovirus infection in collagen diseases. Tokai J Exp Clin Med 2003; 28: 35-8.

32.- Azuma N, Hashimoto N, Yasumitsu A Fukuoka K Yokoyama K Sawada H, et al. CMV infection presenting as a cavitary lung lesion in a patient with systemic lupus erythematosus receiving immunosuppressive therapy. Intern Med 2009; 48: 2145-9.

33.- Tokunaga Y, Takenaka K Asayama R Shibuya T. Cytomegalovirus-induced interstitial pneumonitis in a patient with systemic lupus erythematosus. Intern Med 1996; 35: 517-20.

34.- Suzuki T, Saito S, Hirabayashi Y, Harigae H, Ishii T, Kodera T, et al. Human parvovirus B19 infection during the inactive stage of systemic lupus erythematosus. Intern Med 2003; 42: 5 38-40.

35.- Ramos-Casals M, Cuadrado M J, Alba P, Sanna G, Brito-Zerón P, Bertolaccini L, et al. Acute viral infections in patients with systemic lupus erythematosus. Description of 23 cases and review of the literature. Medicine 2008; 87 : 311-18.

36.- Thong B Y, Koh E T, Chng H H, Chow W C. Outcomes of chronic hepatitis B infection in oriental patients with rheumatic diseases. Ann Acad Med Singapore 2007; 36: 100-5.

37.- Everson G T. Impact of immunosuppressive therapy on recurrence of hepatitis C. Liver Transpl 2002; 8 (10 Suppl 1): S19-27.

38.- Lee Y C, Wang J T, Sun H Y, Chen Y C. Comparisons of clinical features and mortality of cryptococcal meningitis between patients with and without human immunodeficiency virus infection. J Microbiol Immunol Infect 2011; 4: 338-45.

39.- Pappas P G, Perfect J R, Cloud G A, Larsen R A, Pankey G A, Lancaster D J, et al. Cryptococcosis in human immunodeficiency virus-negative patients in the era of effective azole therapy. Clin Infect Dis 2001; 33: 690-9.

40.- Ogawa J, Harigai M, Nagasaka K, Nakamura T, Miyasaka N. Prediction of and prophylaxis against Pneumocystis pneumonia in patients with connective tissue diseases undergoing medium- or high-dose corticosteroid therapy. Mod Rheumatol 2005; 15: 91-6.

41.- Yale S H, Limper A H. Pneumocystis carinii pneumonia in patients without acquired immunodeficiency syndrome: Associated illnesses and prior corticosteroid therapy. Mayo Clin Proc 1996; 71: 5-13.

42.- Russian D A, Levine S J. Pneumocystis carinii pneumonia in patients without HIV infection. Am J Med Sci 2001; 321: 56-65.

43.- Summah H, Zhu Y G, Falagas M E Vouloumanou E K.. $\mathrm{Qu} \mathrm{J} \mathrm{M}$. Use of real-time polymerase chain reaction for the diagnosis of Pneumocystis pneumonia in immunocompromised patients: a meta-analysis. Chin Med J (Engl). 2013; 126: 1965-73.

44.- Rahal M, Moreno M, Villa J. Mucormicosis rino-órbito-cerebral: experiencia en doce años. Rev Otorrinolaringol Cir Cabeza Cuello 2008; 68: $27-34$

45.- Montoya J G, Liesenfeld O. Toxoplasmosis. Lancet 2004; 363: 1965-76.

46.- Zamir D, Amar M, Groisman G, Weiner P. Toxoplasma infection in systemic lupus erythematosus mimicking lupus cerebritis. Mayo Clin Proc 1999; 74: 575-8.

47.- Seta N, Shimizu T, Nawata M, Wada R, Mori K, Sekigawa I, et al. A possible novel mechanism of opportunistic infection in systemic lupus erythematosus, based on a case of toxoplasmic encephalopathy Rheumatology (Oxford) 2002; 41: 1072-3.

48.- Stark D, Barratt J L N, van Hal S, Marriot D, Harkness J, Ellis J T. Clinical significance of enteric protozoa in the immunosuppressed human population. Clin Microb Rev 2009; 22: 634-50.

49.- Goodwin C S. Amoebic colitis exacerbated by steroids. Br Med J 1969 Jul 19; 3 (5663): 174.

50.- Kanani S R, Knight R. Amoebic dysentery precipitated by corticosteroids. Br Med J 1969; 3 (5662): 114. a

51.- Kanani S R, Knight R. R elapsing amoebic colitis of 12 years' standing exacerbated by corticosteroids. Br Med J 1969; 2: 613-4. b

52.- Meisel J L, Perera D R, Meligro C, Rubin C E. Overwhelming watery diarrhea associated with a cryptosporidium in an immunosuppressed patient. Gastroenterology 1976; 70: 1156-60.
53.- Corti M, Villafañe MF, Trione N, Risso D, Abuín J C, Palmieri O. Infección por Strongyloides stercoralis: estudio epidemiológico, clínico, diagnóstico y terapéutico en 30 pacientes. Rev Chilena Infectol 2011; 28: 217-22.

54.- Koo S, Marty F M, Baden L R. Infectious complications associated with immunomodulating biological agents. Hematol Oncol Clin North Am 2011; 25: 117-38.

55.- Galloway J B, Hyrich K L, Mercer L K, Dixon W G, Fu B, Ustianowski A P, et al. Anti-TNF therapy is associated with an increased risk of serious infections in patients with rheumatoid arthritis especially in the first 6 months of treatment: updated results from the British Society for Reumathology Biologics Register with special emphasis on risk in the elderly. Rheumatology 2011; 50: 124-31.

56.- Kroesen S, Widmer A F, Tyndall A, Hasler P. Serious bacterial infections in patients with rheumatoid arthritis under anti-TNF- $\alpha$ therapy. Rheumatology 2003; 42: 617-21.

57.- Wright S A, Taggart A J. Pneumococcal vaccination for RA patients on TNF-alpha antagonists. Rheumatology (Oxford) 2004; 43: 523.

58.- Dixon W G, Watson K, Lunt M, Hyrich K L, Silman A J, Symmons D P. Rates of serious infection, including site-specific and bacterial intracellular infection, in rheumatoid arthritis patients receiving anti-tumor necrosis factor therapy: results from the British Society for Rheumatology Biologics Register. Arthritis Rheum 2006; 54: 2368-76.

59.- Tubach F, Ravaud P, Salmon-Céron D, Petitpain N, Brocq O, Grados F, et al. Emergence of Legionella pneumophila pneumonia in patients receiving tumor necrosis factor- $\alpha$ antagonists. Clin Infect Dis 2006; 43:e95-100.

60.- Abreu C, Magro F, Vilas-Boas F, Lopes S, Macedo G, Sarmento A. Listeria infection in patients on anti-TNF treatment: report of two cases and review of the literature. J Crohns Colitis 2013; 7: 175-82.

61.- Wallis R S. Biologics and infections: lessons from tumor necrosis factor blocking agents. Infect Dis Clin North Am 2011; 25: 895-910.

62.- Wallis R S, Broder M, Wong J, Beenhouwer D. Granulomatous infections due to tumor necrosis factor blockade. Correction. Clin Infect Dis 2004; 39: 1254-5.

63.- Gómez-Reino J J, Carmona L, Descalzo M A BIOBADASER Group. Risk of tuberculosis in patients treated with tumor necrosis factor antagonists due to incomplete prevention of reactivation of latent infection. Arthritis Rheum 2007; 57: 756-61.

64.- Hage C A, Bowyer S, Tarvin S E, Helper D, Kleiman M B, Wheat J L. Recognition, 
diagnosis, and treatment of histoplasmosis complicating tumor necrosis factor blocker therapy. Clin Infect Dis 2010; 50: 85-92.

65.- Smith J A, Kauffman C A. Endemic fungal infections in patients receiving tumor necrosis factor- $\alpha$ inhibitor therapy. Drugs 2009; 69: 1403-15.

66.- Esteve M, Saro C, González-Huix F, Suárez F, Forné M, Viver J M. Chronic hepatitis B reactivation following infliximab therapy in Crohn's disease patients: need for primary prophyalxis. Gut 2004; 53: 1363-5.

67.- Calguneri M, Ozbalkan Z, Ozturk M A, Apras S, Ertenli A I, Kiraz S. Intensified, intermittent, low-dose intravenous cyclosphosphamide together with oral alternate-day steroid therapy in lupus nephritis (long-term outcome). Clin Rheumatol 2006; 25: 782-8.

68.- Uchino M, Yamashita S, Uchino K, Hara A, Koide T, Suga T, et al. Long-term outcome of polymyositis treated with high single-dose alternate-day prednisolone therapy. Eur Neurol 2012; 68: 117-21.

69.- Curtis J J, Galla J H, Woodford S Y, Saykaly R J, Luke R G. Comparison of daily and alternateday prednisone during chronic maintenance therapy: a controlled crossover study. Am J Kidney Dis 1981; 1: 166-71.

70.- Bell M J, Martin L W, Gonzales L L, McEnery P T, West C D. Alternate-day single-dose prednisone therapy: a method of reducing steroid toxicity. J Pediatr Surg 1972; 7: 223-9.

71.- MacGregor R R, Sheagren J N, Lipsett M $\mathrm{B}$, Wolff S M. Alternate-day prednisone therapy. Evaluation of delayed hypersensitivity responses, control of disease and steroid side effects. N Engl J Med 1969; 280: 1427-31.

72.- Dale D C, Fauci A S, Wolff S M. Alternateday prednisone. Leukocyte kinetics and susceptibility to infections. N Engl J Med 1974; 291: 1154-8.

73.- López J, Peña A M, Pérez R, Abarca K. Tenencia de mascotas en pacientes inmunosuprimidos: actualización y consideraciones veterinarias y médicas. Rev Chilena Infectol 2013; 30: 52-62.

74.- França I L, Ribeiro A C, Aikawa N E, Saad C G, Moraes J C, Goldstein-Schainberg C, et al. TNF blockers show distinct patterns of immune response to the pandemic influenza A $\mathrm{H} 1 \mathrm{~N} 1$ vaccine in inflammatory arthritis patients. Rheumatology 2012; 51: 2091-8.

75.- Gelinck L B, van der Bijl A E, Beyer W E, Visser L G, Huizinga T W, van Hogezand R A, et al. The effect of anti-tumor necrosis factor alpha treatment on the antibody response to influenza vaccination. Ann Rheum Dis 2008; 67: 713-6.

76.- Kostianovsky A, Charles P, Alves J F, Goulet M, Pagnoux C, Le Guern V, et al. Immunogenicity and safety of seasonal and 2009 pandemic
A/H1N1 influenza vaccines for patients

with autoimmune diseases: a prospective, monocentre trial on 199 patients. Clin Exp Rheumatol 2012; 30 (1 Suppl 70): S83-9.

77.- Kapetanovic M O, Saxne T, Sjöholm A Truedsson L, Jönsson G, Geborek P. Influence of methotrexate, TNF blockers and prednisolone on antibody responses to pneumococcal polysaccharide vaccine in patients with rheumatoid arthritis. Rheumatology 2006; 45: 106-11.

78.- Kapetanovic M C, Roseman C, Jönsson G, Truedsson L, Saxne T, Geborek P.Antibody response is reduced following vaccination with 7-valent conjugate pneumococcal vaccine in adult methotrexate-treated patients with established arthritis, but not those treated with tumor necrosis factor inhibitors. Arthritis Rheum 2011; 63: 3723-32.

79.- Kapetanovic M C, Roseman C, Jönsson G, Truedsson L. Heptavalent pneumococcal conjugate vaccine elicits similar antibody response as standard 23-valent polysaccharide vaccine in adult patients with RA treated with immunomodulating drugs. Clin Rheumatol 2011; 30: 1555-61

80.- Crnkic Kapetanovic M, Saxne T, Truedsson L, Geborek P. Persistence of antibody response 1.5 years after vaccination using 7-valent pneumococcal conjugate vaccine in batients with arthritis treated with different antirheumatic drugs. Arthritis Res Ther 2013; $15: \mathrm{R} 1$

81.- Elkayam D, Paran D. Caspi D Litinsky I Yaron M, Charboneau D, et al. Immunogenicity and safety of pneumococcal vaccination in patients with rheumatoid arthritis or systemic lupus erythematosus. Clin Infect Dis 2002; 34 : 147-53.

82.- Fica A, Bunster N, Aliaga F, Olivares F, Porte L, Braun S, et al. Bacteremic pneumococcal pneumonia: serotype distribution, antimicrobial susceptibility, severity scores, risk factors and mortality in a single centre in Chile. Braz J Infect Dis 2013; http:// ac.els-cdn.com/S1413867013002328/1-s2.0S1413867013002328-main.pdf? tid=adc1bd48668a-11e3-9ffb-00000aacb362\&acdnat $=1387$ 223335 5cfe7a9beb013263c44a978733fa4345 (en prensa).

83.- Mufson M A, Hughey D F, Turner C E, Schiffman G. Revaccination with pneumococcal vaccine of elderly persons 6 years after primary vaccination. Vaccine 1991; 9: 403-7.

84.- Törling J, Hedlund J, Konradsen H B, Örtqvist Å. Revaccination with the 23-valent pneumococcal polysaccharide vaccine in middle-aged and elderly persons previously treated for pneumonia. Vaccine 2003; 22: 96-103.

85.- Jackson L A, Benson P, Sneller V P, Butler J C, Thompson R S, Chen R T, et al. Safety of revaccination with pneumococcal polysaccharide vaccine. JAMA 1999; 281: 243-8.

86.- de Roux A, Schmöle-Thoma B, Siber G R, Hackell J G, Kuhnke A, Ahlers N, et al. Comparison of pneumococcal conjugate polysaccharide and free polysaccharide vaccines in elderly adults: conjugate vaccine elicits improved antibacterial immune responses and immunological memory. Clin Infect Dis 2008; 46: 1015-23.

87.- Jackson L A, Neuzil K M, Nahm M H, Whitney C G, Yu O, Nelson J C, et al. Immunogenicity of varying dosages of 7-valent pneumococcal polysaccharide-protein conjugate vaccine in seniors previously vaccinated with 23-valent pneumococcal polysaccharide vaccine. Vaccine 2007; 25: 4029-37.

88.- Housden M M, Bell G, Heycock C R Hamilton J. Saravanan Q. Kelly C A. How to reduce morbidity and mortality from chest infections in rheumatoid arthritis. Clin Med 2010; 10: 326-9.

89.- Horsburgh C R Jr. Priorities for the treatment of latent tuberculosis infection in the United States. N Engl J Med 2004; 350: 2060-7.

90.- Dheda K, Udwadia Z F, Huggett J F, Johnson M A, Rook G A W. Utility of the antigen-specific interferon- $\gamma$ assay for the management of tuberculosis. Curr Opin Pulm Med 2005; 11: 195-202.

91.- Beffa P, Zellweger A, Janssens J P, WrightonSmith P, Zellweger J P. Indeterminate results of the T-Spot ${ }^{\mathrm{TM}}$.TB performed under routine field conditions. Eur Respir J 2008; 31: 842-6.

92.- Helwig U, Müller M, Hedderich J, Schreiber E. Corticosteroids and immunosupresive therapy influence the result of the QuantiFERON Gold testing in inflammatory bowel disease patients. $\mathrm{J}$ Crohns Colitis 2012; 6: 419-24.

93.- Bélard E, Semb S, Ruhwald M, Werlinrud A M, Soborg B, Krieger Jennsen F, et al. Prednisolone treatment affects the performance of the QuantiFERON Gold In-tube test and the tuberculin skin test in patients with autoimmune disorders screened for latent tuberculosis infection. Inflamm Bowel Dis 2011; 17 : 2340-9.

94.- Nordgaard-Lassen I, Dahlerup J F, Belard E, Gerstoft J, Kjeldsen J, Kragballe K, et al. Guidelines for screening, prophylaxis and critical information prior to initiating anti-TNFalpha treatment. Dan Med J 2012; 59: C4480.

95.- Carmona L, Gómez-Reino J J; RodríguezValverde V, Montero D, Pascual-Gómez P, Mola E M, et al. Effectiveness of recommendations to prevent reactivation of latent tuberculosis infection in patients treated with tumor necrosis factor antagonists. Arthritis Rheum 2005; 52: 1766-72.

96.- International Union Against Tuberculosis Committee on Prophylaxis. Efficacy of various 
durations of isoniazid preventive therapy for tuberculosis: five years of follow-up in the IUAT trial. Bull World Health Org 1982; 60: 555-64.

97.- Mor A, Bingham CO 3rd, Kishimoto M, Izmirly P M, Greenberg J D, Reddy S, et al. Methotrexate combined with isoniazid treatment for latent tuberculosis is well tolerated in patients with rheumatoid arthritis: experience from an urban arthritis clinic. Ann Rheum Dis 2008; 67: 462-5

98.- Vanhoof J, Landewe S, Van Wijngaerden E, Geusens P. High incidence of hepatotoxicity of isoniazid treatment for tuberculosis

chemoprophylaxis in patients with heumatoid arthritis treated with

methotrexate or sulfasalazine and

anti-tumour necrosis factor inhibitors. Ann Rheum Dis 2003; 62: 1241-2.
99.- Sarzi-Puttini P, Atzeni F, Capsoni F, Lubrano E, Doria A. Drug-induced lupus erythematosus. Autoimmunity 2005; 38: 507-18.

100.- Doria A, Briani C. Lupus: improving long-term prognosis. Lupus 2008; 17: 166-70.

101.- Vassilopoulos D, Apostolopoulou A, Hadziyannis E, Papatheodoridis GV, Manolakopoulos S, Koskinas J, et al. Long-term safety of anti-TNF treatment in patients with rheumatic diseases and chronic or resolved hepatitis B virus infection. Ann Rheum Dis 2010; 69: 1352-5.

102.- Green H, Paul M, Vidal L, Leibovici L. Prophylaxis of Pneumocystis pneumonia in immunocompromised non-HIV-infected patients: Systematic review and meta-analysis of randomized controlled trials. Mayo Clin Proc 2007; 82: 1052-9.
103.- Young A, Koduri G, Batley M, Kulinskaya E Gough A, Norton S, et al. Mortality in rheumatoid arthritis. Increased in the early course of disease, in ischaemic heart disease and in pulmonary fibrosis. Rheumatology 2007; 46: 350-7.

104.- Kelly C, Hamilton J. What kills patients with rheumatoid arthritis? Rheumatology 2007; 46: 183-4.

105.- Coyne P, Hamilton J, Heycock C, Saravanan V, Coulson E, Kelly CA. Acute lower respiratory tract infections in patients with rheumatoid arthritis. J Rheumatol 2007; 34: 1832-6.

106.- Doria A, Iaccarino L, Ghirardello A, Zampieri S, Arienti S, Sarzi-Puttini P, et al. Long-term prognosis and causes of death in systemic lupus erythematosus. Am J Med 2006; 119: 700-6. 